\title{
PERFIL DO SISTEMA DE PRODUÇÃO DE PINHA NOS POLOS DE FRUTICULTURA DA BAHIA, COM ÊNFASE NOS ASPECTOS FITOSSANITÁRIOS DA CULTURA
}

\author{
Alessandro da Silva Oliveira ${ }^{1}$ \\ Maria Aparecida Castellani ${ }^{2}$ \\ Antonio Souza do Nascimento ${ }^{3}$ \\ Aldenise Alves Moreira
}

\section{RESUMO}

O agronegócio da pinha na Bahia é uma atividade econômica primária. O objetivo do presente trabalho foi caracterizar o perfil do sistema de produção de pinha na Bahia e os aspectos fitossanitários da cultura. Foram aplicados questionários aos produtores de pinha de Anagé, Livramento de Nossa Senhora e Presidente Dutra. A amostra foi definida levando em consideração um erro experimental de 8 e $12 \%$. Os resultados indicaram que a cultura está estabelecida em pequenas áreas; os produtores possuem idade acima de 41 anos, baixo nível de escolaridade, com inexpressiva participação em associações e baixo nível tecnológico. A broca-do-fruto foi considerada a principal praga da pinha em Anagé e Livramento de Nossa Senhora, e as cochonilhas em Presidente Dutra, com custos de controle na faixa de 10 a $20 \%$ do total dos problemas fitossanitários. O controle químico é o mais utilizado, com produtos da Classe Toxicológica II e Classe Ambiental I, as pulverizações são iniciadas na fase de frutos pequenos, o que totaliza em torno de cinco pulverizações, sem realização de rotação de inseticidas. Constatou-se desconhecimento geral da Lei dos Agrotóxicos, o que gera muitos casos de descarte irregular de embalagens vazias.

Palavras-chave: Annona squamosa, Cerconota annonella, controle químico, diagnóstico, lei dos Agrotóxicos.

\footnotetext{
${ }^{1}$ Graduado em Engenharia Agronômica (UESB). Especialista em Epidemilogia com ênfase em Defesa Sanitária Vegetal (UNIME). Mestre em Defesa Agropecuária (UFRB). Fiscal Agropecuário (ADAB). E-mail: alessandro.oliveira1@adab.ba.gov.br

${ }^{2}$ Graduada em Engenharia Agronômica (UNESP). Mestre, Doutora e Pós-Doutora em Agronomia (UNESP). Professor Pleno (UESB). E-mail: castellani@uesb.edu.br

${ }^{3}$ Graduado em Agronomia (UFBA). Mestre em Entomologia (USP). Doutor em Ciências (USP). Pesquisador (Embrapa Mandioca e Fruticultura). E-mail: antonio-souza.nascimento@embrapa.br

${ }^{4}$ Graduada em Agronomia (UFAL). Mestre, Doutora e Pós-Doutora em Agronomia (UNESP). Professor Pleno (UESB). E-mail: aldenise.moreira@gmail.com
} 


\title{
PROFILE OF THE ANNONA PRODUCTION SYSTEM IN THE BAHIA FRUITCULTURE POLES, WITH EMPHASIS ON THE PHYTOSANITARY ASPECTS OF THE CULTURE
}

\begin{abstract}
The Annona (Annona squamosa L.) agribusiness in Bahia is a primary economic activity. The objective of this paper was to characterize the profile of the Annona production system of Bahia and the phytosanitary aspects of the culture. Questionnaires were sent to the Annona producers of the cities of Anagé, Livramento de Nossa Senhora and Presidente Dutra. The sample was defined considering an experimental error of 8 to $12 \%$ and the results indicated that the culture is established in small areas managed by farmers older than 41 years old, with negligible participation in associations and low educational and technological levels. The fruit-borer was considered the principal pest of the Annona crops in Anagé and Livramento de Nossa Senhora, while scale insects were predominant in Presidente Dutra, with control costs in the range $10-20 \%$ of all phytosanitary problems. The chemical control is the most used pest control, with Toxicological Class II and Environmental Class I products, by starting spraying in the early stage of the fruits and resulting in a total of about five sprays without performing rotation of insecticides. It was verified that there is a general lack of awareness of the "Pesticide Law", occurring in many cases of irregular disposal of empty containers.
\end{abstract}

Keywords: Annona squamosa,cerconota annonella, chemical control, diagnosis, Pesticide Law.

\section{INTRODUÇÃO}

O Brasil é considerado um importante país produtor e consumidor de frutas tropicais e subtropicais (SÃO JOSÉ, 2003). Dentre as tropicais, as anonáceas (pinha, graviola, cherimóia e atemóia, principalmente) merecem destaque por serem cultivadas em várias regiões do Brasil, gerando emprego e renda (BRAGA SOBRINHO, 2010).

No Nordeste brasileiro, o cultivo da pinha (Annona squamosa L.) encontrase em expansão, principalmente nas condições dos polos de fruticultura irrigados do semiárido, isso acontece devido à possibilidade de obtenção de duas safras anuais e boa remuneração para os fruticultores. Logo, é alta a rentabilidade da cultura da pinha, sua Taxa Interna de Retorno é superior a qualquer taxa de investimento (IBRAF, 2005).Um exemplo é o município de Presidente Dutra, BA, onde a produção de pinha gerou uma renda bruta da ordem de 18 milhões de reais no ano de 2010(ADAB, 2011a), o que colaborou fortemente para que o estado da Bahia seja elevado para a condição de maior produtor nacional dessa fruta.

A cultura da pinha representa uma importante alternativa de produção no semiárido, pois emprega mão-de-obra justamente em regiões com problemas relacionados à seca. Contudo, há carência de dados sobre sua cadeia produtiva, com poucas informações no censo agropecuário realizado pelo Instituto Brasileiro de Geografia e Estatística - IBGE. O Censo Agropecuário de 1996 (IBGE, 1996) indicou a região Nordeste como responsável por $85 \%$ da produção, $89 \%$ da área colhida e $75 \%$ do valor total da produção brasileira de pinha, com destaque para os estados da Bahia (34\%), Pernambuco (17\%), Rio Grande do Norte (13\%) e Alagoas 
(11\%) como os principais em área colhida (NOGUEIRA; MELLO; MAIA, 2005). Em 2006, o IBGE apontou os territórios de identidade de Irecê (Presidente Dutra e Irecê), do Sertão Produtivo (Livramento de Nossa Senhora e Dom Basílio) e de Vitória da Conquista (Anagé) como principais produtores de pinha da Bahia.

No documento publicado pelo IBRAF (2005), sobre análise das principais cadeias produtivas de frutas e da fruticultura orgânica da Bahia, a cadeia produtiva da pinha foi enquadrada inicialmente como secundária, sendo ao final da análise dos indicadores elevada à categoria de dominante, ou seja, passou do status de menor para maior importância econômica. Aspectos tecnológicos, de gestão, comercialização, legislação e padrões de qualidade, de mercado, dentre outros, são apontados no referido documento. A necessidade de desenvolvimento de variedades de pinheira, problemas fitossanitários, inexistência de protocolos de produção integrada, preços praticados, custo de produção, rentabilidade e análise de risco são os principais aspectos abordados.

Quanto aos aspectos fitossanitários, a broca-do-fruto, a broca-dosponteiros, ácaros, cochonilha, lagarta e moscas-das-frutas são consideradas as principais pragas (IBRAF, 2005; GALLO et al., 2002;BRAGA SOBRINHO, 2010).Do ponto de vista dos tratamentos fitossanitários, os principais problemas referem-se à ausência de registros de agrotóxicos no MAPA (Ministério da Pecuária, Agricultura e Abastecimento) para combater essas pragas e doenças. Essa falta de agrotóxicos registrados tem dificultado a adoção de sistemas de gestão de qualidade, como a Produção Integrada de Frutas (PIF), tal fato traz o risco de o produto ser contestado tanto pelo mercado interno como pelo mercado internacional (IBRAF, 2005).

A situação da agricultura brasileira é bastante precária quanto ao uso correto e seguro de agrotóxicos. Tal condição, provavelmente, é mais acentuada na produção de culturas cujas informações sobre a questão fitossanitária são ainda insuficientes. Esse é o caso da pinha, em sua produção, verifica-se a ocorrência de pragas e doenças durante todo o seu ciclo. Estes problemas são combatidos com agrotóxicos sem registro no MAPA, cuja comprovação de eficiência e segurança é desconhecida.

Embora se destaquem importantes regiões produtoras de anonáceas no Brasil, a escassez de levantamentos sistemáticos de sua produção por parte de órgãos oficiais dificulta uma análise mais atualizada e específica a respeito da evolução, comercialização e participação dessas frutas no agronegócio brasileiro (NOGUEIRA; MELLO; MAIA, 2005.).

As estratégias adotadas para controle das pragas nas diferentes culturas e sistemas de cultivo variam em função das condições socioeconômicas dos produtores e das práticas agronômicas utilizadas em cada cultura (RICHETTI; MORAES; ÁVILA, 2009.). Há lacunas de informações sobre o perfil dos produtores de anonáceas relacionadas à faixa etária, escolaridade, participação em organizações de classe, dentre outras que possam subsidiar uma compreensão do nível tecnológico praticado nos cultivos em especial àqueles relacionados ao controle de pragas. Como exemplo da importância dessas informações, pode-se tomar o cultivo da uva, cuja cadeia produtiva é dificultada pelo baixo grau de escolaridade dos produtores, e pelo fato de apresentarem idade acima de 50 anos. Esses fatores tornam-se obstáculos para a realização de mudanças nos controles e processos da viticultura, além da explícita tendência, em algumas propriedades, de abandono da atividade por falta de mão-de-obra pelo êxodo do jovem do meio rural (ZARTH et al., 2011).

Atualmente, o agronegócio da pinha na Bahia é considerado uma atividade econômica dominante (IBRAF, 2005), mas que apresenta falta de dados oficiais tanto sobre o produtor, como sobre os aspectos fitossanitários da cultura. Assim, o 
objetivo deste trabalho é caracterizar o perfil de produção da pinha em suas principais zonas, bem como de seus aspectos fitossanitários, com ênfase na brocado-fruto, buscando subsidiar estudos sobre extensão de uso de produtos para controle da praga no cultivo da fruta.

\section{PROCEDIMENTOS METODOLÓGICOS}

A pesquisa foi realizada no período de setembro a outubro de 2012. Foram aplicados questionários aos produtores de pinha das principais regiões produtoras da Bahia: Anagé, Livramento de Nossa Senhora e Presidente Dutra. O questionário apresenta dezenove perguntas estruturadas da seguinte forma: opção de múltipla escolha, resposta livre, dicotômica (duas opções, "sim" ou "não") aplicados por faixa (etária, de escolaridade e tamanho da área), com disponibilização de fotos dos sintomas ocasionados pelas pragas e doenças (MALHOTRA, 2006).

As perguntas envolveram os seguintes aspectos: 1) perfil do produtor (faixa etária, escolaridade, tamanho da área, participação em organizações sociais, comercialização e nível tecnológico); 2) fitossanitários da cultura (pragas e doenças, principais pragas, broca-do-fruto, custo de controle de pragas e custo de controle da broca); 3) métodos de controle e controle químico (tipos de controle, produtos, classificação toxicológica, classificação ambiental, início de pulverização, número de aplicações, rotação de produto e ingrediente ativo - I.A. em revisão ou proibido); 4) conhecimentos sobre a Lei dos Agrotóxicos, tríplice lavagem e descarte de embalagens.

A classificação do nível tecnológico da produção foi baseada nas práticas culturais adotadas na condução da lavoura, tais como irrigação, poda, polinização, adubação, manejo de plantas daninhas e manejo de pragas e doenças. $O$ nível tecnológico foi classificado como alto (todas essas práticas eram adotadas pelo produtor), médio (três ou mais práticas adotadas) e baixo (apenas uma ou duas práticas adotadas).

A definição da população total de produtores foi realizada com base no cadastro dos mesmos junto à Agência Estadual de Defesa Agropecuária da Bahia ADAB. O tamanho da população amostrada foi definida considerando-se um erro experimental de 8 e 12\%, variando em função da região (Tabela1).

O número de amostras em função dos referidos erros experimentais foi calculado por meio da fórmula abaixo:

$n_{0}=\frac{1}{E_{0}^{2}} \quad \Rightarrow \quad n=\frac{N * n_{0}}{N+n_{0}}$

Em que:

$N=$ tamanho da população,

$E_{0}^{2}=$ erro amostral tolerável, $n_{0}=$ primeira aproximação do tamanho da amostra e

$n=$ tamanho da amostra. 
Tabela 1 - População total (№) e população amostrada (№ e \%) de produtores de Pinha e respectivo erro experimental (\%), em função do polo de produção.

\begin{tabular}{lcccc}
\hline Polo de & População Total & População Amostrada & Erro Experimental \\
\cline { 2 - 5 } Produção & No & № & $\%$ & $\%$ \\
\hline Anagé & 03 & 03 & 100,0 & 8 \\
Livramento de & 17 & 16 & 94,1 & 8 \\
Nossa Senhora & & & & 12 \\
Presidente Dutra & 260 & 77 & 22,3 & - \\
\hline Total & 280 & & &
\end{tabular}

Os dados obtidos foram tabulados por meio do cálculo das porcentagens das respostas de cada quesito em relação ao total de entrevistas e à região produtora, a partir desses foram elaboradas tabelas contendo os maiores percentuais das questões do diagnóstico com análise descritiva de todos os dados.

\section{RESULTADOS E DISCUSSÃO}

\subsection{PERFIL DO PRODUTOR}

A maioria dos produtores de pinha da Bahia $(71,5 \%)$ tem mais de 50 anos. Em Anagé, a totalidade desses produtores possui mais de 50 anos, já em Livramento e em Presidente Dutra66\% e 75\%, respectivamente, possuem idade acima de 41 anos (Tabela 2).O que se pode perceber em todos os polos, é um baixo percentual de agricultores mais jovens (20 a 30 anos).Apenas $1 \%$ em Livramento de Nossa Senhora e 4,0\% em Presidente Dutra. Esses dados concordam com estudos realizados por Brandão (2009) sobre o cultivo de manga, cujos resultados indicaram que a maioria (80\%) dos produtores de Livramento de Nossa Senhora que participam do monitoramento de moscas-das-frutas, também, apresentam faixa etária acima dos 41 anos. Perfil semelhante é encontrado no Rio Grande do Sul, onde $63 \%$ dos produtores têm mais de 41 anos (LIMA et al., 2009). Dados do Programa de Educação Sanitária da ADAB caracterizaram a população rural de Lapão (que pertence ao território de identidade de Irecê), com maioria nas faixas etárias de 31 a 40 (45\%) e de mais de 50 anos (47\%) (ADAB, 2011b). Porém, em comparação feita entre os produtores de pinha da Bahia com os horticultores do Paraná da região de Londrina, observa-se grande diferença na faixa etária, pois Londrina possui apenas 35\% acima de 41 anos (MARQUES, 2010).

Quanto à escolaridade, a maioria destes trabalhadores possui apenas o ensino fundamental completo $(53,2 \%)$ (Tabela 2$)$, seguido do ensino médio incompleto $(27,3 \%)$, ensino médio completo $(9,1 \%)$, ensino fundamental incompleto $(3,9 \%)$, graduação $(3,9 \%)$ e mestrado $(1,3 \%)$.

No entanto, o nível de escolaridade é mais elevado em Anagé e mais baixo nos outros polos, onde a maioria tem apenas o ensino fundamental completo, existem produtores analfabetos em Livramento de Nossa Senhora e com ensino fundamental incompleto em Presidente Dutra (Tabela 2). Em estudos realizados por Brandão (2009), em Livramento de Nossa Senhora, entre os produtores de manga, verificou-se que $48 \%$ dos produtores que participam do monitoramento oficial de moscas-das-frutas possuem ensino médio completo e 14\% possuem graduação, enquanto aqueles que não participam do processo, na sua maioria (72\%), possuem o ensino médio completo. Na microrregião de Dourados foi verificada maioria de produtores com ensino superior $(58,8 \%)$ enquanto um menor grupo possuía ensino 
fundamental (5,9\%) (RICHETTI; MORAES; ÁVILA, 2009), características bem diferentes dos produtores de pinha do Estado da Bahia. Apresentam baixa escolaridade, também produtores de pêssego, no Rio Grande do Sul, com um número de 68,9\% com ensino fundamental incompleto (LIMA et al., 2009). $\mathrm{Na}$ cultura do caju no Ceará, há elevado percentual de produtores que sequer começaram o ensino fundamental e muitos outros que iniciaram os estudos e não conseguiram concluí-los. Logo, a maioria destes trabalhadores é constituída de analfabetos ou de pessoas com o ensino fundamental incompleto (LIMA et al., 2010). Perfil diferente é encontrado nos produtores de grãos da Microrregião Dourados, MS, onde a maioria dos produtores entrevistados tinha nível superior de escolaridade (RICHETTI; MORAES; ÁVILA, 2009).

Tabela 2 - Porcentagem (\%) de produtores de pinha do Estado da Bahia e das principais regiões produtoras, em função das questões diagnóstico sobre perfil da produção de pinha.

\begin{tabular}{lcccc}
\hline $\begin{array}{l}\text { Questões do } \\
\text { diagnóstico }\end{array}$ & Bahia & Anagé & $\begin{array}{c}\text { Livramento de } \\
\text { Nossa Senhora }\end{array}$ & Presidente Dutra \\
\hline Faixa etária & $\begin{array}{c}71,5 \% \text { acima } \\
\text { de } 50 \text { anos }\end{array}$ & $\begin{array}{c}100 \% \text { acima } \\
\text { de } 50 \text { anos }\end{array}$ & $\begin{array}{c}66 \% \text { acima de } \\
41 \text { anos }\end{array}$ & $\begin{array}{c}75 \% \text { acima de } 41 \\
\text { anos }\end{array}$ \\
\hline $\begin{array}{c}53,2 \% \\
\text { ensino } \\
\text { fundamental } \\
\text { completo }\end{array}$ & $\begin{array}{c}100 \% \text { ensino } \\
\text { médio } \\
\text { completo }\end{array}$ & $\begin{array}{c}60 \% \text { ensino } \\
\text { fundamental } \\
\text { completo }\end{array}$ & $\begin{array}{c}58 \% \text { ensino } \\
\text { fundamental } \\
\text { completo }\end{array}$ \\
\hline $\begin{array}{l}\text { Tamanho da } \\
\text { área }\end{array}$ & $\begin{array}{c}100 \% \text { acima } \\
\text { de } 10 \text { ha }\end{array}$ & $\begin{array}{c}56 \% \text { entre } 1 \text { a } 5 \\
\text { ha }\end{array}$ & $\begin{array}{c}73 \% \text { entre } 1 \text { a } 5 \\
\text { ha }\end{array}$ \\
\hline $\begin{array}{l}\text { Participação } \\
\text { organização } \\
\text { social }\end{array}$ & $\begin{array}{c}72,4 \% \text { não } \\
\text { participam }\end{array}$ & $\begin{array}{c}67 \% \\
\text { participam }\end{array}$ & $\begin{array}{c}75 \% \text { não } \\
\text { participam }\end{array}$ & $\begin{array}{c}74 \% \text { não } \\
\text { participam }\end{array}$ \\
\hline $\begin{array}{l}\text { Forma de } \\
\text { comercialização }\end{array}$ & $\begin{array}{c}62,3 \% \text { ao } \\
\text { atravessador }\end{array}$ & $\begin{array}{c}100 \% \text { ao } \\
\text { atacadista }\end{array}$ & $\begin{array}{c}56 \% \text { ao } \\
\text { atacadista }\end{array}$ & $\begin{array}{c}71 \% \text { ao } \\
\text { atravessador }\end{array}$ \\
\hline $\begin{array}{l}\text { Nível } \\
\text { tecnológico }\end{array}$ & $56,4 \%$ baixo & $67 \%$ alto & $50 \%$ baixo & $61 \%$ baixo \\
\hline Fonte: dados da pesquisa.
\end{tabular}

Fonte: dados da pesquisa.

O perfil dos produtores de pinha da Bahia e de uva do Sudoeste do Paraná é semelhante quanto à idade e escolaridade. Segundo Zarth et al. (2011), 65\% dos viticultores têm acima de 50 anos, o que dificulta trabalhos que exigem maior força braçal. O baixo grau de escolaridade dos produtores de uva (maioria até a oitava série do ensino fundamental), associado à idade acima de 50 anos são fatores que dificultam a realização de mudanças nos controles e processos da atividade, além do fato de que, em algumas propriedades, há o abandono da atividade por falta de mão-de-obra por causa do êxodo do jovem do meio rural (ZARTH et al., 2011). A baixa escolaridade também é relatada nos dados do Programa de Educação Sanitária da $A D A B$ no município de Lapão onde existe uma maioria formada por analfabetos funcionais (37\%) (ADAB, 2011b). Na população de produtores de hortaliças da região de Londrina, a maioria $(66,7 \%)$ está compreendida entre o ensino fundamental incompleto e completo, o que caracteriza baixa escolaridade (MARQUES, 2010).

A cultura da pinha na Bahia está estabelecida em pequenas áreas de até 5 ha $(77,2 \%)$ (menos de 1 ha: $10,1 \%$ e de 1 até 5 ha: $67,1 \%)$. O total de $16,5 \%$ dos produtores cultiva pinha em áreas de10 a 20 ha $(8,9 \%)$ e de 5 a 10 ha $(7,6 \%)$. Cultivos de pinha em áreas de 20 a 30 ha e mais de 30 ha representam uma minoria 
de $6,4 \%$ (Tabela 2). Esses dados concordam parcialmente com aqueles apresentados pelo IBGE (2006) em nível de Brasil, que indicaram predomínio de cultivos de até 5 ha $(85,1 \%)$, e da Bahia, que revelaram que a maioria dos cultivos também é de até 5 ha (78,5\%). Dados do IBGE (2006) indicam que em outros estados do Nordeste, como Pernambuco, Alagoas, Rio Grande do Norte e Ceará, a maioria dos cultivos também está distribuída em áreas de até 5 ha, com destaque para Pernambuco, Alagoas e Rio Grande do Norte onde predominam cultivos em áreas que não atingem 1 ha. Os dados de Minas Gerais e São Paulo seguem a mesma tendência dos estados do Nordeste (maioria com até 5 ha), no entanto São Paulo apresenta maior percentual de cultivos com 5 a 10 ha (17,39\%). A cultura da videira no Sudoeste do Paraná também está concentrada em pequenos cultivos de até 1 ha $(69,86 \%)$, com no máximo 3 ha (ZARTH et al., 2011), diferindo um pouco das áreas cultivadas com pinhas, sendo estas relativamente um pouco maiores. Os cultivos de pêssego de Pelotas, RS, estão implantados em áreas de até 10 ha $(60,7 \%)$, indicando que essa fruteira está estabelecida em áreas médias (LIMA et al., 2009).

Quando são considerados os percentuais de cultivos nas faixas de menos de 1 ha e de 1 a 5 ha, verificam-se mudanças no perfil do produtor baiano ao longo dos últimos seis anos, com aumento de áreas cultivadas de 1 a 5 ha e redução daquelas menores que 1 ha, pois em 2006 os valores eram de $47,6 \%$ e $31,5 \%$, respectivamente (IBGE, 2006). A grande maioria das pequenas áreas cultivadas (1 a 5 ha) está distribuída nos polos de Presidente Dutra e Livramento de Nossa Senhora, e são bem maiores no polo de Anagé onde medem acima de 10 ha (Tabela 2). Em relação a 2006, constata-se uma mudança no perfil do produtor bastante acentuada no polo de Presidente Dutra, com significativa redução das áreas cultivadas com menos de 1 ha (de $23,5 \%$ para $7 \%$ ) e de 10 a 20 ha (de $45,6 \%$ para 3\%) (IBGE, 2006).

A participação dos produtores de pinha em associações ou outros organismos não governamentais é incipiente, pois apenas $18,4 \%$ dos produtores participam de associações de produtores, enquanto que a maioria $(72,4 \%)$ dos fruticultores respondeu que não participa de nenhuma instituição não governamental ou associação. A implantação e, ou, o fortalecimento de cooperativas locais, gerenciadas por fruticultores, bem como ampliação da participação dos fruticultores nesses órgãos, serviria de suporte técnico, de fomento à produção e apoio aos processos de comercialização, conforme constatado para produção de outras cadeias produtivas, como a batata (REICHERT et al., 2011).

A participação em associação comunitária ocorre com $5,3 \%$ dos produtores, enquanto a participação em cooperativa (1,3\%), em sindicato $(1,3 \%)$ ou em ambos e também em associação comunitária $(1,3 \%)$, totalizam $3,3 \%$ da população de produtores (Tabela 2). Nesse aspecto o perfil do produtor de pinha da Bahia se assemelha ao perfil do produtor de abacaxi da Paraíba, onde mais de $70 \%$ dos produtores não participam de nenhuma forma de organização (MACÊDO et al., 2011). No entanto, comparando-se com produtores de uva do Paraná, verifica-se que os perfis são bastante diferentes nesse quesito, pois $91,78 \%$ desses produtores estão envolvidos em cooperativas ou associações e $61,64 \%$ em cooperativa ou associações ligadas diretamente à uva (ZARTH et al., 2011), já os produtores de Lapão, BA, apresentam alto nível de envolvimento em entidade sociais (93\%)(ADAB, 2011b).

Novamente, neste quesito, se constatam diferenças entre os pólos frutícolas, que indicam ser a participação dos produtores em organizações sociais maior em Anagé (67\%) e semelhante em Presidente Dutra (25\%) e Livramento de Nossa Senhora (26\%) (Tabela 2). Em Livramento de Nossa Senhora é costume os 
fruticultores participarem de associações e cooperativas, no entanto os produtores de pinha não se inserem neste contexto.

Infelizmente, a maioria dos produtores de pinha da Bahia comercializa seu produto para os atravessadores $(62,3 \%)$, o que demonstra falta de organização em cooperativas e associações, conforme indicado anteriormente. Situação semelhante é verificada na cadeia produtiva do abacaxi na Paraíba, onde prevalece a forma tradicional de comercialização via terceiros, atingindo 75,83\% (BARREIRO NETO et al., 2002, citados por MACÊDO et al., 2011). Vendas diretas aos atacadistas e nas feiras livres são praticadas por 36,4\% e 1,3\% dos produtores, respectivamente (Tabela 2). Essa situação é mais acentuada no polo de Presidente Dutra, onde $71 \%$ dos produtores vendem diretamente aos atravessadores; em Livramento de Nossa Senhora, a distribuição da comercialização a atacadistas e atravessadores apesar de próximas, apresenta leve vantagem para venda direta aos atacadistas (56,6\%) em relação aos atravessadores (44\%) (Tabela 2).

Os entrepostos oficiais no comércio atacadista no comércio de frutas estão sendo substituídos, em parte, por centrais de compras mais modernas e administradas pela iniciativa privada, como as grandes redes de supermercados, com aquisição de frutas diretamente dos produtores ou então de fornecedores independentes (NOGUEIRA; MELLO; MAIA, 2005.).É importante considerar que a melhoria da organização das atividades do setor comercial pode gerar consequências positivas retirando os pequenos produtores do patamar de subsistência ou dependentes totalmente de atravessadores e intermediários (IBRAF, 2005).

Quanto ao nível tecnológico da produção, que o próprio produtor se enquadra, os dados indicaram predomínio de baixo nível tecnológico $(56,4 \%)$, sendo $39 \%$ e $5 \%$ com médio e alto níveis tecnológicos, respectivamente (Tabela 2). Esse alto percentual geral de produtores que conduzem seus cultivos com baixo nível tecnológico é reflexo, principalmente, da situação verificada em Presidente Dutra, onde a maioria dos produtores (61\%) se enquadrou nessa categoria, ao contrário do que se verifica em Anagé (Tabela 2). Esses dados estão associados ao baixo nível de escolaridade dos produtores, limitando, provavelmente, sua evolução e aperfeiçoamento profissional, bem como integração nas associações de classe, com reflexos em vários indicadores da cadeia produtiva da pinha.

Essa situação é preocupante e pode ser limitante para o desenvolvimento satisfatório das cadeias produtivas de frutas, pois segundo Richetti, Moraes e Ávila (2009) o desenvolvimento dos processos administrativos passa pela evolução do nível de escolaridade dos produtores rurais, pois a instrução facilita a tomada de decisão quanto às mudanças tecnológicas que ocorrem no setor agrícola.

\subsection{ASPECTOS FITOSSANITÁRIOS}

Ao se considerar o total dos entrevistados, a maioria (95\%) afirmou possuir problemas fitossanitários nos seus cultivos de pinha, sendo este fato verificado nas três regiões produtoras (Tabela 3).Apenas dois produtores de cada uma das regiões de Livramento de Nossa Senhora e de Presidente Dutra afirmaram pela resposta "não" quando questionados sobre possuir problemas com doenças e pragas na lavoura de pinha. 
Tabela 3 - Porcentagem (\%) de produtores de pinha do Estado da Bahia e das principais regiões produtoras, em função das questões diagnóstico sobre aspectos fitossanitários da cultura.

\begin{tabular}{|c|c|c|c|c|}
\hline $\begin{array}{l}\text { Questões do } \\
\text { diagnóstico }\end{array}$ & Bahia & Anagé & $\begin{array}{l}\text { Livramento de } \\
\text { Nossa Senhora }\end{array}$ & $\begin{array}{l}\text { Presidente } \\
\text { Dutra }\end{array}$ \\
\hline $\begin{array}{l}\text { Tem problemas } \\
\text { com pragas e } \\
\text { doenças }\end{array}$ & $95 \% \operatorname{sim}$ & $100 \% \operatorname{sim}$ & $88 \% \operatorname{sim}$ & $97 \% \operatorname{sim}$ \\
\hline $\begin{array}{l}\text { Principais } \\
\text { pragas }\end{array}$ & $\begin{array}{l}22,3 \% \\
\text { cocho- } \\
\text { nilhas }\end{array}$ & $\begin{array}{l}100 \% \text { broca-do- } \\
\text { fruto } \\
100 \% \text { broca-da- } \\
\text { haste }\end{array}$ & $\begin{array}{l}100 \% \text { broca-do- } \\
\text { fruto } \\
67 \% \text { cochonilhas } \\
40 \% \text { broca-da-raiz } \\
13 \% \text { ácaros }\end{array}$ & $\begin{array}{l}66 \% \\
\text { cochonilhas } \\
58 \% \text { ácaros } \\
54 \% \text { broca-da- } \\
\text { raiz } \\
54 \% \text { broca-da- } \\
\text { haste }\end{array}$ \\
\hline $\begin{array}{l}\text { Broca-do-fruto } \\
\text { como praga } \\
\text { principal }\end{array}$ & $57,9 \% \operatorname{sim}$ & $100 \% \operatorname{sim}$ & $94 \% \operatorname{sim}$ & $54 \%$ não \\
\hline $\begin{array}{l}\text { Custo de } \\
\text { controle de } \\
\text { pragas em } \\
\text { relação ao custo } \\
\text { total de } \\
\text { produção* }\end{array}$ & $\begin{array}{l}42 \% \text { de } 10 \\
\text { até } 20 \%\end{array}$ & $\begin{array}{l}33 \% \text { até } 10 \% \\
33 \% \text { de } 10 \text { até } \\
20 \% \\
33 \% \text { de } 20 \text { até } \\
30 \%\end{array}$ & $73 \%$ até $10 \%$ & $\begin{array}{l}47 \% \text { de } 10 \text {, até } \\
20 \%\end{array}$ \\
\hline $\begin{array}{l}\text { Custo de } \\
\text { controle da } \\
\text { broca-do-fruto } \\
\text { em relação ao } \\
\text { custo total do } \\
\text { controle de } \\
\text { pragas }\end{array}$ & $\begin{array}{l}31,7 \% \text { de } \\
10 \text { até } 20 \%\end{array}$ & $\begin{array}{l}33 \% \text { até } 10 \% \\
33 \% \text { de } 10 \text { até } \\
20 \% \\
33 \% \text { de } 20 \text { até } \\
30 \%\end{array}$ & $50 \%$ até $10 \%$ & $\begin{array}{l}41 \% \text { de } 10 \text { até } \\
20 \%\end{array}$ \\
\hline
\end{tabular}

Com relação às pragas, cochonilhas, broca-do-fruto, broca-da-raiz, brocada-haste e ácaros foram apontadas como principais, sendo que em cada polo a importância relativa de cada uma foi diferente, destacando-se a broca-do-fruto e broca-da-haste em Anagé (100\%), broca-do-fruto em Livramento de Nossa Senhora $(100 \%)$ e cochonilhas (66\%), broca-da-raiz (54\%) e broca-da-haste (54\%) em Presidente Dutra. (Tabela 3). Percentuais menores de produtores relacionaram a broca-do-ponteiro $(1,8 \%)$, mosca branca $(1,8 \%)$, fungos de folhas $(1,4 \%)$, broca-dasemente $(0,9 \%)$, fusariose $(0,9 \%)$, seca de ramos $(0,5 \%)$ e pulgão $(0,5 \%)$ como problemas fitossanitários na cultura. De modo geral, as pragas citadas estão relacionadas nas literaturas que abordam o assunto (IBRAF, 2005; GALLO et al., 2002; BRAGA SOBRINHO, 2010).

A broca-da-haste parece se constituir problema em Anagé e em Presidente Dutra, onde $100 \%$ e $54 \%$ dos produtores, respectivamente, enquadraram a praga como principal, o mesmo não acontece em Livramento. Por outro lado, cochonilhas, broca-da-raiz e ácaros foram relatados apenas pelos produtores de Presidente Dutra e Livramento, sendo 66\%, 54\% e 58\% para Presidente Dutra e 67\%, 40\% e $13 \%$ para Livramento de Nossa Senhora, respectivamente (Tabela 3). Esses dados indicam que as regiões diferem quanto aos tipos principais de problemas fitossanitários, o que, provavelmente, indica situações de maior desequilíbrio nos 
pomares de Presidente Dutra pela maior importância dos ácaros. Muitas espécies de ácaros são favorecidas pela aplicação de agrotóxicos (BARROS et al., 2007), especialmente do grupo dos piretroides ou pelos seus subprodutos formados durante a degradação (TRINDADE; CHIAVEGATO, 1999), os quais alteram aspectos do seu comportamento e fisiologia propiciando o aumento populacional. Quando questionados sobre a importância da broca-do-fruto, 57,9\% de todos os produtores responderam que "sim", ou seja, trata-se uma praga chave e $42,1 \%$ responderam "não", valores muito próximos e que refletem a situação que ocorreu em Presidente Dutra, onde 54\% responderam "não". Nas outras regiões, a quase totalidade dos produtores considerou a broca-do-fruto uma praga importante (Tabela 3).

Com relação à participação do custo de controle dos problemas fitossanitários no custo total de produção, boa parte dos produtores $(42,1 \%)$ indicou custos de 10 a 20\%; 30,3\% afirmaram que o custo representa menos de $10 \%$; $15,8 \%$ dos produtores gastam entre 20 e $30 \%$; acima de $30 \%$ apenas $10,5 \%$ dos produtores e 1,3\% dos produtores não controlam, não gerando custos (Tabela 3). Em Anagé, as respostas foram igualmente distribuídas nas três primeiras classes; em Livramento, a maioria considerou que os custos não chegam a $10 \%$; em Presidente Dutra a situação mostrou-se diferente, com distribuição por todas as classes, inclusive aquela que os custos estão entre 40 e $50 \%$, predominando a faixa de 10 a $20 \%$ (Tabela 3). Quanto ao custo de controle da broca em relação ao custo de controle das outras pragas, $61 \%$ dos produtores responderam que é de até $20 \%$, sendo que $22 \%$ dos produtores informaram que o custo é de 20 a $30 \%$ (Tabela 3). Na microrregião de Dourados, MT, Richetti, Moraes, Ávila (2009) verificaram pouca preocupação com o custo das aplicações e nível de dano provocado pela praga e, como consequência, alto número de aplicações de agrotóxicos.

\subsection{MÉTODOS DE CONTROLE E CONTROLE QUÍMICO}

Quando interrogados sobre os tipos de controle usados para a broca-dofruto, $47,6 \%$ dos produtores responderam que usam exclusivamente o controle químico, enquanto $31 \%$ afirmaram associar os métodos químicos e culturais, e mais $14,3 \%$, exclusivos de Presidente Dutra, não realizam nenhum tipo de controle (Tabela 4). Os métodos químicos e biológicos foram apontados pela minoria dos produtores $(7,1 \%)$. No entanto, não se pode ter certeza de que os produtores compreenderam exatamente do que se trata o controle biológico, pois não há, até o momento, uma tecnologia de controle biológico aplicado à cultura.

Em Anagé, a totalidade dos produtores associa os métodos culturais e químicos, enquanto em Livramento de Nossa Senhora a maioria só utiliza o controle químico (Tabela 4), mesma situação observada na microrregião de Dourados, MT, onde a maioria realiza o manejo de pragas exclusivamente com controle químico (RICHETTI; MORAES; ÁVILA, 2009.), o que pode ser denominado de manejo de inseticidas. Informações mais detalhadas sobre os produtos podem ser observadas na Tabela 5.

Quanto aos produtos, 19 itens foram citados pelos produtores, com destaque para os inseticidas Connect (17,5\%), Engeo Pleno (15,8\%), Polytrin $(15,8 \%)$, Karate $(7 \%)$ e óleos minerais $(15,8 \%)$. Os demais estão bastante distribuídos entre as respostas, sendo citada inclusive a urina de bovídeo (Tabela 4). Considerando as regiões produtoras, observa-se que em Anagé apenas dois itens foram citados (Fastac e Altacor), enquanto em Presidente Dutra pelo menos 10 foram relacionados pelos produtores (Tabela 5). Pesquisas têm demonstrado que 0 
consumo de agrotóxicos depende do tipo de cultura explorada na região (LIMA et al., 2011).

Tabela 4 - Porcentagem (\%) de produtores de pinha do Estado da Bahia e das principais regiões produtoras, em função das questões diagnóstico sobre métodos de controle e controle químico de pragas.

\begin{tabular}{|c|c|c|c|c|}
\hline $\begin{array}{l}\text { Questões do } \\
\text { Diagnóstico }\end{array}$ & Bahia & Anagé & $\begin{array}{l}\text { Livramento de } \\
\text { Nossa Senhora }\end{array}$ & Presidente Dutra \\
\hline $\begin{array}{l}\text { Métodos de } \\
\text { controle }\end{array}$ & $\begin{array}{c}47,6 \% \\
\text { químico }\end{array}$ & $\begin{array}{c}100 \% \text { químico } \\
\text { e cultural }\end{array}$ & 79\% Químico & $\begin{array}{c}36 \% \text { químico } \\
36 \% \text { químico e } \\
\text { cultural }\end{array}$ \\
\hline $\begin{array}{l}\text { Produtos* } \\
\text { usados } \\
\text { (químico, } \\
\text { biológico, } \\
\text { outros) }\end{array}$ & 19 itens & 2 itens & 7 itens & 10 itens \\
\hline $\begin{array}{l}\text { Classificação } \\
\text { Toxicológica dos } \\
\text { Produtos } \\
\text { Químicos e } \\
\text { Biológicos }\end{array}$ & $\begin{array}{l}46 \% \text { III - } \\
\text { media- } \\
\text { namente } \\
\text { tóxico }\end{array}$ & $\begin{array}{c}100 \% \text { III - } \\
\text { medianamente } \\
\text { tóxico }\end{array}$ & $\begin{array}{c}45 \% \text { II - } \\
\text { altamente tóxico }\end{array}$ & $\begin{array}{c}63 \% \text { III - } \\
\text { medianamente } \\
\text { tóxico }\end{array}$ \\
\hline $\begin{array}{l}\text { Classificação } \\
\text { Ambiental dos } \\
\text { Produtos } \\
\text { Químicos e } \\
\text { Biológicos }\end{array}$ & $\begin{array}{c}26 \% \text { I - } \\
\text { altamente } \\
\text { tóxico ao } \\
\text { meio } \\
\text { ambiente }\end{array}$ & $\begin{array}{c}100 \% \text { II - } \\
\text { muito perigoso } \\
\text { ao meio } \\
\text { ambiente }\end{array}$ & $\begin{array}{c}64 \% \text { II - muito } \\
\text { perigoso ao } \\
\text { meio ambiente }\end{array}$ & $\begin{array}{c}56 \% \text { I - altamente } \\
\text { tóxico ao meio } \\
\text { ambiente }\end{array}$ \\
\hline $\begin{array}{l}\text { Início } \\
\text { daaplicação }\end{array}$ & $\begin{array}{c}54,3 \% \\
\text { frutos bem } \\
\text { pequenos }\end{array}$ & $\begin{array}{c}67 \% \text { frutos } \\
\text { bem pequenos }\end{array}$ & $\begin{array}{l}71 \% \text { na fase de } \\
\text { botão }\end{array}$ & $\begin{array}{l}78 \% \text { frutos bem } \\
\text { pequenos }\end{array}$ \\
\hline $\begin{array}{l}\text { Número de } \\
\text { aplicações }\end{array}$ & $\begin{array}{c}25 \% \\
5 \\
\text { aplicações }\end{array}$ & $\begin{array}{c}67 \% \\
4 \text { aplicações }\end{array}$ & $\begin{array}{c}36 \% \\
5 \text { aplicações }\end{array}$ & $\begin{array}{c}21 \% \\
5 \text { aplicações }\end{array}$ \\
\hline $\begin{array}{l}\text { Rotação de } \\
\text { produtos }\end{array}$ & $\begin{array}{c}54,3 \% \\
\text { Não } \\
\text { realiza } \\
\text { rotação } \\
\end{array}$ & $\begin{array}{c}100 \% \text { realizam } \\
\text { rotação }\end{array}$ & $\begin{array}{l}50 \% \text { realiza } \\
\text { rotação }\end{array}$ & $\begin{array}{l}67 \% \text { não realiza } \\
\text { rotação }\end{array}$ \\
\hline $\begin{array}{l}\text { Ingrediente Ativo } \\
\text { (em revisão ou } \\
\text { proibido) }\end{array}$ & quatro & ------ & dois & dois \\
\hline
\end{tabular}

${ }^{*}$ Os produtos estão listados na Tabela 5.

Fonte: dados da pesquisa 
Tabela 5 - Produto, modo de ação, ingrediente ativo (IA), grupo químico dos produtos usados na pinha no Estado da Bahia.

\begin{tabular}{|c|c|c|c|}
\hline $\begin{array}{l}\text { Produto } \\
\text { Comercial }\end{array}$ & Modo de ação & $\begin{array}{l}\text { Ingrediente Ativo } \\
\text { (IA) }\end{array}$ & Grupo químico \\
\hline Connect & Sistêmico & $\begin{array}{c}\text { Beta-ciflutrina }+ \\
\text { imidacloprido }\end{array}$ & $\begin{array}{l}\text { Neonicotinóide + } \\
\text { piretróide }\end{array}$ \\
\hline Engeo Pleno & $\begin{array}{l}\text { Sistêmico, contato } \\
\text { e ingestão. }\end{array}$ & $\begin{array}{c}\text { Lambda-cialotrina + } \\
\text { tiametoxam }\end{array}$ & $\begin{array}{c}\text { Neonicotinóide + } \\
\text { piretróide }\end{array}$ \\
\hline Polytrin & Contato e ingestão & Cipermetrina + profenofós & $\begin{array}{c}\text { Organofosforado + } \\
\text { piretróide }\end{array}$ \\
\hline Óleo mineral & Contato & Óleo mineral & $\begin{array}{l}\text { Hidrocarbonetos } \\
\text { alifáticos }\end{array}$ \\
\hline Karate & Contato e ingestão & Lambda-cialotrina & Piretróide \\
\hline Agro oil & Contato & Óleo vegetal & $\begin{array}{l}\text { Ésteres de ácidos } \\
\text { graxos }\end{array}$ \\
\hline Decis & Contato e ingestão & Deltametrina & Piretróide \\
\hline Cyptrin 250 CE & Contato e ingestão & Cipermetrina & Piretróide \\
\hline Piretroíde & ---- & ---- & Piretróide \\
\hline Folisuper & Contato e ingestão & Parationa-metílica & Organofosforado \\
\hline Vertimec $18 \mathrm{EC}$ & Contato e ingestão & Abamectina & Avermectina \\
\hline Altacor & Contato e ingestão. & Clorantraniliprole & Antranilamida \\
\hline Fastac $100 \mathrm{SC}$ & Contato e ingestão & Alfa-cipermetrina & Piretróide \\
\hline Stron & Sistêmico & Metamidofós & Organofosforado \\
\hline Siptran ${ }^{\star}$ & Seletivo & Atrazina & Organofosforado \\
\hline Tamaron* & Sistêmico & Metamidofós & Organofosforado \\
\hline Agritoato 400 & Sistêmico & Dimetoato & Organofosforado \\
\hline $\begin{array}{l}\text { Úrina de } \\
\text { bovideo }\end{array}$ & ---- & ---- & ----- \\
\hline
\end{tabular}

${ }^{*}$ Retirado do mercado em função da Resolução da ANVISA RDC n. 01/2011.

Fonte: dados da pesquisa

De modo geral, observa-se que a maioria dos inseticidas pertence ao grupo químico dos piretróides ou de mistura de piretróide com neonicotinóide (Connect e Engeo Pleno) ou com organofosforado (Polytrin). Estes três inseticidas foram citados por $49,1 \%$ dos produtores. Os produtos neonicotinóides estão em fase de reavaliação pelo IBAMA (IBAMA, 2012), em função de seus efeitos adversos sobre abelhas (LIMA; ROCHA, 2012). Dos produtos citados pelos produtores, o Stron e Tamaron, ambos à base de metamidofós, saíram do mercado em junho de 2012 (ANVISA, 2011).

Vale ressaltar que, dentre os produtos citados para controle da broca, Siptran (Atrazina) é um herbicida, seu uso como inseticida indica falta de conhecimentos básicos do produtor em relação aos produtos fitossanitários, o que implica na possibilidade de uso incorreto e inseguro de inseticidas, podendo gerar riscos à saúde do trabalhador e do consumidor. Como a cultura da pinha não possui produtos registrados observa-se que os produtores das diferentes regiões utilizam produtos mais relacionados às culturas principais da região, provavelmente pela maior disponibilidade nas lojas de produtos agropecuários.

Observa-se que $46 \%$ dos agrotóxicos são da Classe III (medianamente tóxicos) e $21 \%$ da Classe IV (pouco tóxico), $20 \%$ da Classe II (altamente tóxico) e $13 \%$ da Classe I (extremamente tóxico) (Tabela 4). Em Anagé, a totalidade dos produtos é medianamente tóxica, enquanto em Livramento observa-se uma distribuição entre as classes toxicológicas, com predominância de produtos altamente tóxicos. A situação de Presidente Dutra é mais próxima à de Anagé 
(Tabela 4). Em Boa Vista, RO, para os horticultores que cultivam em ambiente protegido a distribuição é $13 \%$ extremante tóxico, $21,7 \%$ altamente tóxico, $26,1 \%$ medianamente tóxico e $39,1 \%$ pouco tóxico (LIMA et al., 2011).

Considerando-se a classificação ambiental, os produtos são classificados como altamente tóxico ao meio ambiente (46\%) e muito perigoso ao meio ambiente (45\%), totalizando $91 \%$ dos inseticidas citados pelos produtores, com predominância de produtos altamente tóxico em Presidente Dutra e muito perigoso em Livramento e presidente Dutra (Tabela 4). Para os produtores de hortaliças de Boa Vista, RO, a distribuição é $91,3 \%$ nas classes I, II e III podendo trazer sérias consequências para ao meio ambiente (LIMA et al., 2011).

As pulverizações para controle da broca são iniciadas quando os frutos estão bem pequenos, com até $2 \mathrm{~cm}$ aproximadamente (54,3\% dos produtores) ou então desde a fase de botão floral (42,9\%). Contudo, uma minoria de produtores inicia as pulverizações em frutos maiores (Tabela 4). Quando se observa o comportamento do produtor de cada região, verifica-se que em Livramento a maior parte dos produtores (71\%) inicia as aplicações na fase de botão, em contraste com as demais regiões onde a maioria inicia na fase de frutos pequenos, sendo $67 \%$ paraAnagé e $78 \%$ para Presidente Dutra (Tabela 4).

Assim, de modo geral, observa-se que há conhecimento da biologia geral do inseto, uma vez que a fêmea inicia suas posturas em frutos pequenos, mas em condições de altas infestações, as oviposições também ocorrem nas flores (BITTENCOURT; MATTOS SOBRINHO; PEREIRA, 2007). Na literatura há indicações para iniciar as pulverizações nas inflorescências, para o caso da graviola, e frutos pequenos e grandes, a cada 15 dias (GALLO et al., 2002) ou a cada 10 ou 15 dias (BRAGA SOBRINHO, 2010).Quanto ao número de pulverizações para controle da broca-do-fruto, há uma grande variação entre as respostas dos produtores com menores percentuais para os extremos, ou seja, apenas uma aplicação $(2,8 \%)$ e 15 aplicações (2,8\%). Grande parte dos produtores $(47,2 \%)$ afirmou que realiza $4(22,2 \%)$ e 5 aplicações (25\%). O total de $30,5 \%$ dos produtores pulverizam $6(8,3 \%), 7(8,3 \%), 8(8,3 \%)$ ou $10(5,6 \%)$ vezes durante o ciclo de produção (Tabela 4).

Um aspecto de manejo importante na prevenção de seleção de populações de insetos e ácaros resistentes aos inseticidas e acaricidas é a rotação de produtos com sítios de ação diferenciados. A maioria dos produtores de pinha $(54,3 \%)$ não realiza rotação de inseticidas, sendo esta situação reflexo da região de Presidente Dutra, onde $67 \%$ dos produtores não realizam rotação. Em Anagé, a totalidade dos produtores afirmou realizar essa tática de manejo e em Livramento a rotação é praticada por $50 \%$ dos produtores (Tabela 4 ).

\subsection{USO CORRETO DE AGROTÓXICOS}

O conhecimento da Lei dos Agrotóxicos e afins é um importante mecanismo que leva ao uso seguro e correto dos produtos fitossanitários. Dos produtores de pinha entrevistados, 50,7\% afirmam que já leram e que conhecem o conteúdo da Lei; $17 \%$ afirmam ter tomado conhecimento da Lei pelos meios de comunicação e que sabem alguma coisa sobre ela; $16 \%$ não conhecem a Lei, mas já escutaram alguma coisa a respeito; $9 \%$ conhecem a lei, mas não dominam seu conteúdo; e 7\%, conhecem a lei, tomaram conhecimento pelos meios de comunicação, mas não sabem bem do que se trata (Tabela 6). 
Tabela 6 - Síntese dos tipos de controle aspectos fitossanitários da cultura da pinha no Estado da Bahia e das principais regiões produtoras.

\begin{tabular}{|c|c|c|c|c|}
\hline $\begin{array}{l}\text { Questões } \\
\text { do } \\
\text { Diagnóstico }\end{array}$ & Bahia & Anagé & $\begin{array}{l}\text { Livramento de } \\
\text { Nossa Senhora }\end{array}$ & $\begin{array}{l}\text { Presidente } \\
\text { Dutra }\end{array}$ \\
\hline $\begin{array}{l}\text { Lei de } \\
\text { Agrotóxicos }\end{array}$ & $\begin{array}{l}50,7 \% \text { Sim, já } \\
\text { li, conhecem } \\
\text { seu conteúdo. }\end{array}$ & $\begin{array}{c}\text { 33\% sim, já li, } \\
\text { conhecem seu } \\
\text { conteúdo. } \\
\text { 33\% sim, já li, mas } \\
\text { não domino o seu } \\
\text { conteúdo. } \\
\text { 33\% sim, já tomei } \\
\text { conhecimento pelos } \\
\text { meios de } \\
\text { comunicação e sei } \\
\text { alguma coisa sobre } \\
\text { ela. }\end{array}$ & $\begin{array}{l}\text { 44\% não, mas já } \\
\text { escutei alguma } \\
\text { coisa a respeito. }\end{array}$ & $\begin{array}{l}\text { 58\% sim, já li, } \\
\text { conhecem seu } \\
\text { conteúdo. }\end{array}$ \\
\hline $\begin{array}{l}\text { Tríplice } \\
\text { lavagem }\end{array}$ & $\begin{array}{c}79,4 \% \\
\text { realizam }\end{array}$ & $100 \%$ realizam & $92 \%$ realizam & $67 \%$ realizam \\
\hline $\begin{array}{l}\text { Descarte } \\
\text { embalagens } \\
\text { vazias }\end{array}$ & $\begin{array}{l}31,4 \% \\
\text { Devolvem na } \\
\text { central de } \\
\text { recebimento }\end{array}$ & $\begin{array}{l}100 \% \text { devolvem na } \\
\text { central de } \\
\text { recebimento }\end{array}$ & $\begin{array}{c}43 \% \text { queima } \\
43 \% \text { devolve a } \\
\text { loja que } \\
\text { comprou }\end{array}$ & $\begin{array}{c}44 \% \text { devolvem } \\
\text { na central de } \\
\text { recebimento }\end{array}$ \\
\hline
\end{tabular}

Fonte: dados da pesquisa

Em relação às regiões produtoras, em Presidente Dutra há predomínio de produtores que conhecem a Lei, já em Livramento a situação é mais grave, pois a maioria apenas escutou alguma coisa a respeito (Tabela 6). Dados do Programa de Educação Sanitária da ADAB indicaram que em Lapão a população de produtores em sua maioria não conhecia lei de agrotóxicos (55\%) (ADAB, 2011b).

Com relação à tríplice lavagem, a maioria dos produtores $(79,4 \%)$ faz uso da prática. Condição semelhante é observada em Livramento de Nossa Senhora e Anagé, e com menor percentual em Presidente Dutra (67\%) (Tabela 6). Em levantamentos com produtores de manga de áreas monitoradas e não monitoradas, em Livramento de Nossa Senhora, verificou-se que $82 \%$ e $98 \%$, respectivamente, realizam a tríplice lavagem (BRANDÃO, 2009), assemelhando-se ao resultado do presente trabalho para pinha no mesmo município (92\%). Em Boa Vista, RO, os produtores de hortaliças em ambiente protegido não realizam a tríplice lavagem em sua maioria $(90,67 \%)$ e $100 \%$ não dão a destinação correta (LIMA et al., 2011).

Quanto ao descarte de embalagens, apenas $31 \%$ dos produtores devolvem na central de embalagens e $28,8 \%$ devolvem nas lojas agropecuárias. Um dado surpreendente é que $31 \%$ dos produtores queimam as embalagens, 5,7\% guardam e $2,9 \%$ enterram na propriedade, totalizando quase $40 \%$ de descarte totalmente irregular e ilegal. Foi encontrado o descarte regular apenas em Anagé (Tabela 6). Produtores de pêssego de Pelotas, RS, também praticam a queima (11,8\%), o abandono na lavoura (3\%) e enterro $(4,4 \%)$ das embalagens, porém de forma menos acentuada (LIMA et al., 2009). Cerca de 10\% dos produtores de manga de Livramento de Nossa Senhora queimam as embalagens; $70 \%$ dos produtores de áreas não monitoradas deixam as embalagens no campo, em contraste com apenas $4 \%$ das áreas monitoradas (BRANDÃO, 2009). Os produtores de Lapão apresentam, em sua maioria, comportamento adequado à legislação, com $89 \%$ dos produtores 
que entregam as embalagens na central de recebimento de embalagens vazias, e apenas $11 \%$ desrespeitam a Lei (ADAB, 2011b).

\section{CONCLUSÕES}

- A cultura da pinha na Bahia está estabelecida em pequenas áreas, há o predomínio de produtores com idade acima de 41 anos, baixo nível de escolaridade, baixa participação em associações e, ou, cooperativas e uso de baixo nível tecnológico nos cultivos;

- O polo de Anagé destaca-se por apresentar produtores com maior nível de escolaridade e tecnológico e maiores conhecimentos sobre a Lei dos Agrotóxicos;

- A importância dos problemas fitossanitários varia em função das regiões produtoras; com custos de controle da ordem de 10 a $20 \%$ do custo total de produção, ficando neste mesmo patamar a participação do custo de controle da broca-do-fruto em relação ao custo com problemas fitossanitários;

- O controle químico é o mais utilizado mesmo não existindo nenhum inseticida registrado para o controle da broca-do-fruto, sem realização de rotação de inseticidas pela maioria dos produtores;

- Há um desconhecimento geral da Lei dos Agrotóxicos pelos produtores, o que gera muitos casos de descarte irregular de embalagens;

- Constata-se a necessidade de políticas públicas que envolvam ações de Educação Sanitária e Extensão Rural na cadeia produtiva da pinha para o Estado da Bahia.

\section{REFERÊNCIAS}

AGÊNCIA ESTADUAL DE DEFESA AGROPECUÁRIA DA BAHIA. Bahia que Produz - Defesa Sanitária Vegetal. Relatório. Salvador: ADAB-DDSV, 2011a. p. 42.

AGÊNCIA ESTADUAL DE DEFESA AGROPECUÁRIA DA BAHIA. Diagnóstico educativo sobre a conduta dos produtores rurais do município de Lapão, com relação ao uso correto e seguro dos agrotóxicos. Relatório. Irecê: Programa de Educação Sanitária, 2011b. p. 49.

AGÊNCIA NACIONAL DE VIGILÂNCIA SANITÁRIA. Defere inclusão de novo acondicionamento, cancelamento de registro da apresentação, cancelamento de registro do medicamento e retificação de publicação, conforme relação anexa. Resolução - RE n. 143, de 14 de Janeiro de 2011. p. 56. Seção 1. Diário Oficial da União (DOU) de 17 de Janeiro de 2011.

BARROS, R. et al. Desequilíbrio biológico do ácaro-rajado Tetranychus urticae Koch, 1836 (Acari: Tetranychidae) após aplicações de inseticidas em algodoeiro. Arquivos Instituto Biológico, São Paulo, v. 74, n. 2, p.171-174, 2007.

BITTENCOURT, M. A. L.; MATTOS SOBRINHO, C.; PEREIRA, M. J. B. Biologia, danos e táticas de controle da broca-da-polpa das anonáceas. Revista Bahia Agrícola, v. 8, n. 1, p. 16-17, 2007. 
BRAGA SOBRINHO, R. Potencial de exploração de anonáceas no nordeste do Brasil. In: Semana Internacional da Fruticultura, Floricultura e Agroindústria. $17^{\mathrm{a}}$. set 2010.

<http://www.ceinfo.cnpat.embrapa.br/arquivos/artigo_3425.pdf>. Acesso em 15 out. 2012.

BRANDÃO, M. H. S. T. Levantamento do de agrotóxicos e utilização de equipamentos de proteção individual entre os agricultores do polo de fruticultura de Livramento de Nossa Senhora, Bahia. 2009. 68 f. Monografia. (Especialização em Epidemiologia com ênfase em Defesa Sanitária Vegetal). União Metropolitana de Educação e Cultura. Lauro de Freitas.

GALLO, D. et al. Entomologia agrícola. Piracicaba: FEALQ, 2002.

INSTITUTO BRASILEIRO DO MEIO AMBIENTE E DOS RECURSOS NATURAIS RENOVÁVEIS. Comunicado. Brasília, 2012 (Comunicado nำ139).

INSTITUTO BRASILEIRO DE GEOGRAFIA E ESTATÍSTICA. Censo agropecuário. Rio de Janeiro, 2006. Disponível em: $<$ http://www.ibge.gov.br/home/estatistica/economia/agropecuaria/censoagro/default.s htm>. Acesso em 16 out. 2012.

INSTITUTO BRASILEIRO DE FRUTAS. Programa SEBRAE de cadeias produtivas agroindustriais: estudo da cadeia produtiva de fruticultura do Estado da Bahia - Análise das principais cadeias produtivas de frutas e da fruticultura orgânica no contexto baiano. São Paulo, jan. 2005. Disponível em: <http://www2.ba.sebrae.com.br/banco/documentos/ cadeiasprodutivas/Estudo\%20da\%20Cadeia\%20Produtiva\%20de\%20Fruticultura\%2 0do\%20Estado\%20da\%20Bahia\%20-\%20An\%C3\%A1lises.pdf>. Acesso em 15 out. 2012.

LIMA, M. C.; ROCHA, S. A. Efeitos dos agrotóxicos sobre as abelhas silvestres no Brasil. Proposta metodológica de acompanhamento. Brasília: IBAMA, 2012.

LIMA, A. C. S. et al. Diagnóstico fitossanitário e de práticas associadas ao uso de agrotóxicos nas hortas em ambiente protegido em Boa Vista - Roraima. Revista Agroambiental On-line, v. 5, n. 2, p. 124-133. 2011. Disponível em: <www.Agroambiente.ufrb.br>. Acesso em 13 out. 2012.

LIMA, C. A. B. et al. A. D. Diagnóstico da exposição ocupacional a agrotóxicos na principal região produtora de pêssego para indústria do Brasil. Ciência Rural, Santa Maria. v. 39, n. 3, p. 900-903, 2009.

LIMA, S. S. et al. Nível tecnológico e fatores de decisão para adoção de tecnologia na produção de caju no Ceará. Revista de Economia e Agronegócios, v. 6, n. 1, p.121-145, 2010.

MACÊDO, L. A. S. et al. Perfil socioeconômico dos produtores de abacaxi do município de Lagoa de Dentro, Paraíba. Geoambiente on-line. n. 17. jul./dez. 2011. Disponível em: <www2.jatai.ufg.br/índex.php/geoambiente>. Acesso em 15 out. 2012. 
MALHOTRA, N.K. Pesquisa de marketing: uma orientação aplicada. 4. ed. Porto Alegre: Bookman, 2006.

MARQUES, C. R. G.; NEVES. P. M. J.; VENTURA, M. U. Diagnóstico do conhecimento de informações básicas para o uso de agrotóxicos por produtores de hortaliças da região de Londrina. Ciência Agrária, Londrina, v. 31, n. 3, p. 547-556, 2010.

NOGUEIRA, E. A. E; MELLO, N. T. C. de; MAIA, M. L. Produção e comercialização de anonáceas em São Paulo e Brasil. Informações Econômicas, São Paulo, v. 35, n. 2, p. 51-54, 2005.

REICHERT, L. J. et al. Caracterização e análise da produção de batata nos municípios de São Lourenço do Sul - Brasil e Sanlúcar de Barrameda - Espanha. Extensão Rural, Santa Maria, n. 22, p. 133-158, 2011.

RICHETTI, A.; MORAES, G. C.; ÁVILA, C. J. Perfil do produtor e manejo de pragas na microrregião Dourados. Documento 102. Dourados: Embrapa Agropecuária Oeste, 2009.

SÃO JOSÉ, A. R. Cultivo e mercado da graviola, Fortaleza: Instituto Frutal, 2003.

TRINDADE, M. L. B.; CHIAVEGATO, L. G. Efeitos de subprodutos da fotodegradação da deltametrina na população de Tetranychus urticae Koch (Acari: Tetranychidae). Anais da Sociedade Entomólogica do Brasil, v. 28, n. 3, p. 511517, 1999.

ZARTH, N. A. et al. Perfil sócio-econômico da viticultura da região sudoeste do Paraná. Synergismus Scyentifica, v. 6, n. 1, p. 10, 2011. 